\title{
Catalysis in motion
}

\author{
The transportation sector represents a vibrant area of application for researchers in the catalysis community. This \\ Insight presents a selection of topical articles showcasing the potential of catalysis research in an area of crucial \\ societal relevance.
}

W hen thinking about an ancient chariot or a sailing ship, it becomes clear that transportation has always played a crucial role in human activities. Throughout the centuries, thanks to remarkable technological development, the transportation infrastructure has experienced continuous transformation, opening up impressive possibilities. Large distances can be now covered in relatively short time spans - think, for instance, about intercontinental flights. Moreover, massive amounts of goods and raw materials can be moved to very distant locations on Earth and, why not even to space, if projects such as asteroid mining are going to become a reality ${ }^{1}$. It does not matter if by air, land or water: transportation is one of the key enabling factors for both the modern economy and globalization.

The awakening of a societal sensitivity towards the environmental impact of human activity, however, has brought special attention to modern transportation, which heavily relies on fossil fuels and shares responsibility for the increasing levels of environmental pollution. As a consequence, the sector has been challenged to introduce solutions to increase its sustainability. The scientific community is obviously expected to do its part. Different scientific disciplines can contribute from their traditional areas of knowledge. For instance, materials science and nanotechnology are the best candidates to generate lightweight components for commercial vehicles, thereby improving fuel comsumption ${ }^{2}$. And catalysis has certainly a major role to play within the forthcoming revolution in the transportation industry.

This issue of Nature Catalysis is dedicated to transportation and features a selection of Reviews, Perspectives, Comments and Articles that reveal the multifaceted implications of catalysis for this strategic sector. We present contributions from both academic and industrial authors. In fact, as we already stated in a previous editorial, the partnership between the academic world and the private enterprise remains a crucial and enabling factor for the introduction of new technologies into society ${ }^{3}$.

Catalysis has a direct impact on several aspects of the transportation sector, from fuel production and refinement to power generation and emissions mitigation. We certainly could only cover a small fraction of topics related to transportation and catalysis and had to leave behind prominent examples, such as the fluid cracking or reforming of oil, and many others where catalysis may be involved, such as the production of lubricants, tire rubber, and so on. Instead, we have set the focus on its sustainable side and environmental impact: emissions control, production of hydrocarbon fuels and fuel cell powered engines.

\section{"Catalysis has a direct impact on several aspects of the transportation sector, from fuel production and refinement to power generation and emissions mitigation."}

Emissions control is one of the central themes of the issue and will be the subject of two Comments, two Reviews and one Article. These provide a historical overview and discuss the state-of-the-art in automotive exhaust catalysis, including three- and four-way catalysts, lean $\mathrm{NO}_{x}$ traps or selective catalytic reduction catalysts. The need for decreasing the content of platinum-group metals (PGM) in $\mathrm{CO}$ oxidation catalysts is also thoroughly reviewed, highlighting the most recent advances. In an Article, Andrew Getsoian and colleagues demonstrate improved performance of the $\mathrm{Rh} / \mathrm{Al}_{2} \mathrm{O}_{3}$ three-way catalyst by solution atomic layer deposition of titania or zirconia promoters. An underlying motif recognizable while reading these contributions is that regulation has been crucial in driving the development of emission control technologies. However, the present is confronting us with new and more complicated challenges which require an updated discussion on how transportation should be developed to fulfil the needs of our globalized society. This is finely illustrated in one of our comment contributions, which places such an analysis under the prism of the United Nations sustainable development goals programme.
Furthermore, as the sustainable procurement of hydrocarbon fuels remains an important issue for the transportation sector, we also included two research articles that focus on Fischer-Tropsch synthesis and the production of high-octane gasoline from biomass. In the former, Peter Ellis and co-workers present a simple $\mathrm{Co} / \alpha-\mathrm{Al}_{2} \mathrm{O}_{3}$ catalyst that achieves high performance and stability for syngas conversion to $\mathrm{C}_{5+}$ products, without the addition of precious metal promoters. Daniel Ruddy and colleagues, on the other hand, show how highoctane gasoline or jet fuel can be obtained by a biorefinery concept that features the incorporation of $\mathrm{C}_{4}$ products during dimethyl ether homologation as the key step.

While internal combustion engines will continue to have a role in the coming years, potentially renewable electrical power for transportation is of ever-increasing importance. Therefore, we have dedicated a section to electric vehicles, discussing the advances in fuel cell catalyst technology in two Comments, one Perspective and one Review. Hydrogen fuel cell cathode catalysts are the main focus. The achievements and challenges of PGM-based and PGMfree catalysts for the oxygen reduction reaction are analysed in great detail, and the production and storage of hydrogen is also briefly discussed based on the goals of the H2@Scale initiative of the US Department of Energy. The recent progress in solid oxide fuel cells and their potential role in the transportation sector is also analysed in the form of a Perspective.

As discussed above, the topics contained in this Insight can only give a small taste of what is happening in the area of transportation. We hope nevertheless that the broad catalysis community will find these articles of inspiration to reinvigorate research efforts that can benefit this crucial sector of our society. We wish you a pleasant reading.

Published online: 11 July 2019

https://doi.org/10.1038/s41929-019-0329-0

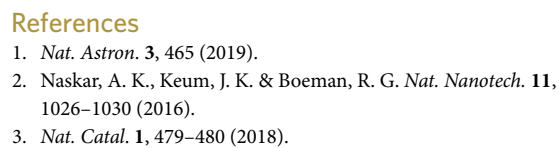

